\title{
Establishment of a Rating Program for Pre- and Post-Fabricated Windows
}

\section{Simulation, Testing, Quality Control, Certification, and Labeling Requirements}

$\begin{array}{ll}\text { GB Parker } & \text { TS Mapes } \\ \text { B Shah } & \text { CN Bloyd }\end{array}$

August 2011

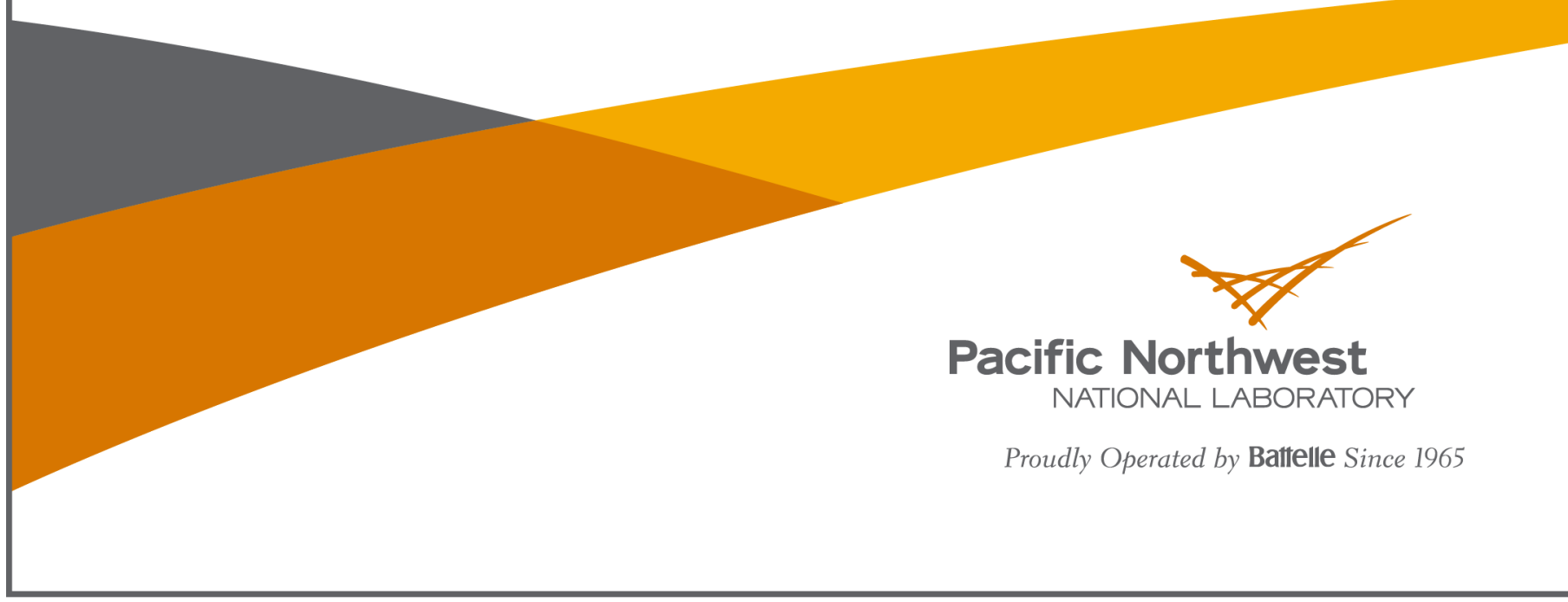




\title{
DISCLAIMER
}

This report was prepared as an account of work sponsored by an agency of the United States Government. Neither the United States Government nor any agency thereof, nor Battelle Memorial Institute, nor any of their employees, makes any warranty, express or implied, or assumes any legal liability or responsibility for the accuracy, completeness, or usefulness of any information, apparatus, product, or process disclosed, or represents that its use would not infringe privately owned rights. Reference herein to any specific commercial product, process, or service by trade name, trademark, manufacturer, or otherwise does not necessarily constitute or imply its endorsement, recommendation, or favoring by the United States Government or any agency thereof, or Battelle Memorial Institute. The views and opinions of authors expressed herein do not necessarily state or reflect those of the United States Government or any agency thereof.

\author{
PACIFIC NORTHWEST NATIONAI, I.ABORATORY \\ operated by \\ BAT'TELLE \\ for the \\ UNITFD STATES DEPARTMFNT OF FNFRGY \\ under Contract DE-AC05-76RL01830
}

Printed in the United States of America

Available to DOE and DOE contractors from the

Office of Scientific and Technical Information,

P.O. Box 62, Oak Ridge, TN 37831-0062;

ph: (865) 576-8401

fax: (865) 576-5728

email: reports@) adonis.osti.gov

\author{
Available to the public from the National Technical Information Service, \\ U.S. Department of Commerce, 5285 Port Roy al Rd., Springfield, VA 22161 \\ ph: (800) 553-6847 \\ fax: (703) 605-6900 \\ email: orders $(a)$ ntis.fedworld.gov \\ online ordering: http://www.ntis.gov/ordering.htm
}




\section{Establishment of a Rating Program for Pre- and Post-Fabricated Windows}

Simulation, Testing, Quality Control, Certification, and Labeling Requirements

August 2011

TS Maples

CN Bloyd

$\begin{array}{ll}\text { BB Parker } & \text { CNah } \\ & \text { CN Bloyd }\end{array}$

Prepared for

the U.S. Department of Energy

under Contract DE-AC05-76RL01830

Pacific Northwest National Laboratory

Richland, Washington 99352

\footnotetext{
${ }^{1}$ WinBuild, Inc., Fairfax, Virginia.
} 


\section{Summary}

This document was prepared to support the Smart Buildings-Material Testing and Rating Centres (SB-2) activity of the Asia-Pacific Economic Cooperation (APEC) Energy Smart Communities Initiative (ESCI). The ESCI was put forward by APEC Leaders at the 2010 meeting in Japan. APEC is the premier forum for facilitating economic growth, cooperation, trade and investment in the Asia-Pacific region. This document addresses the testing and certification of building products and equipment to support building energy codes, focusing specifically on energy-efficient factory-built windows.

In the context of this document, efficient windows would be windows made with insulating glass (IG) and an efficient frame assembly. The minimum efficiency metric (or thermal performance) for these windows is not quantified in this document and would generally be established by a governmental agency. These windows are used primarily in the residential (housing) sector and consist of the insulating glass unit (IGU) and frame assembled in a factory and shipped to the installation site ready to be installed. The IGU is generally produced by a totally separate manufacturing process that is not a part of the window manufacturing/assembly plant.

This document sets forth a proposed structure for an APEC economy to establish a testing, rating, certification, and labeling program for efficient factory-built windows. Each of these four elements of an energy-efficient windows industry in a country is discussed in detail in this document. In summary, the following is a list of recommendations and requirements for establishing a viable windows industry:

1. Establish an overarching governing body to oversee a windows simulation/testing, rating, certification and labeling infrastructure;

2. Establish the criteria used to test windows and components;

3. Ensure the manufacturers and site-assembled windows are of consistent quality and meet the ratings;

4. Create a labeling process and meaningful label to affix to products, displays, and other relevant materials;

5. Ensure the installed windows comply with the established codes and standards.

Where appropriate, examples are given of well-established international programs that can be a template for establishing a viable energy-efficient windows industry. This document also gives recommendations and identification of equipment to be used in a windows performance testing facility.

Finally, where appropriate or known, the authors present additional detail and relevant examples by specific APEC economies. We note where well-established international programs can serve as a template to design and facilitate a viable energy-efficient windows industry in the APEC regions. 


\section{Acknowledgments}

Funding for this report was provided by the U.S. Department of Energy (DOE), Energy Efficiency and Renewable Energy (EERE), Building Technology Program (BTP). The authors would like to thank Mr. Marc LaFrance, EERE/BTP, for his support and guidance throughout the project. The authors would also like to thank Ray McGowan, Senior Program Manager, National Fenestration Rating Council (NFRC), for reviewing the document and providing inputs. 


\section{Contents}

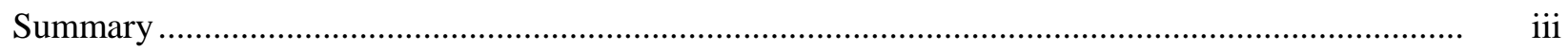

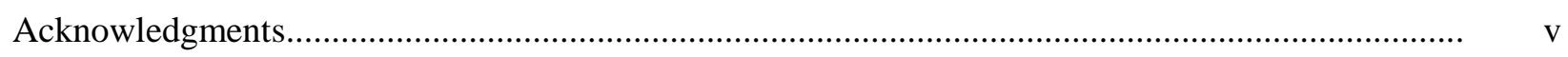

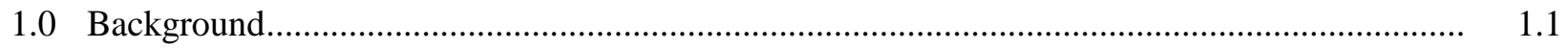

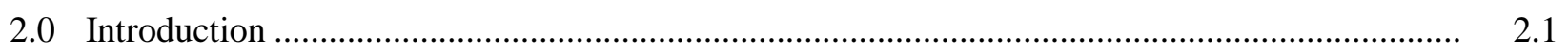

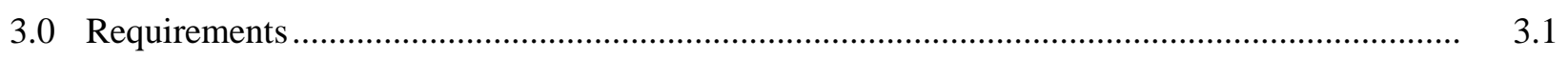

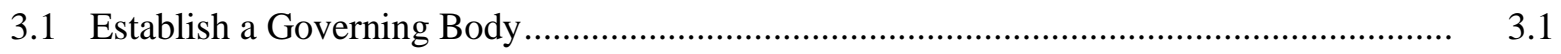

3.2 Establish Performance Metrics............................................................................. 3.2

3.3 Establish Testing Laboratories and Certifying Agencies .............................................. 3.3

3.4 Create a Labeling Process ....................................................................................... 3.3

3.5 Ensure Proper Window Installation ............................................................................... 3.3

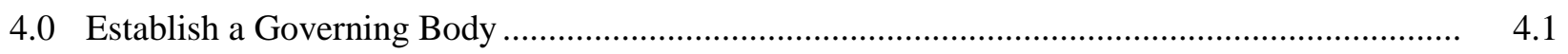

4.1 Board Responsibilities........................................................................................... 4.1

4.2 Governing Body Responsibilities.......................................................................... 4.2

5.0 Establish Mandatory/Minimum Performance Rating and Certification Criteria ....................... 5.1

5.1 Selecting Window Product Attributes for Performance Rating and Certification .............. 5.1

6.0 Establish Simulation, Testing and Certification Organizations ........................................... 6.1

6.1 Testing and Certification of Windows Products ......................................................... 6.1

6.2 Attributes of the Testing/Certification Laboratory ......................................................... 6.2

6.2.1 Equipment for Laboratory Testing …............................................................. 6.2

6.3 Pre-Fabricated Certification of Windows-The Process .................................................... 6.3

6.4 Post-Fabricated Certification of Windows-The Process................................................. 6.5

6.4.1 CMA Procedure: How It Works................................................................... 6.5

6.5 Inspection of Windows Manufacturing Plants ............................................................... 6.5

6.6 Certification of an Integrated Glass Unit Manufacturing Plant........................................... 6.6

7.0 Create a Labeling Process and Labels ............................................................................ 7.1

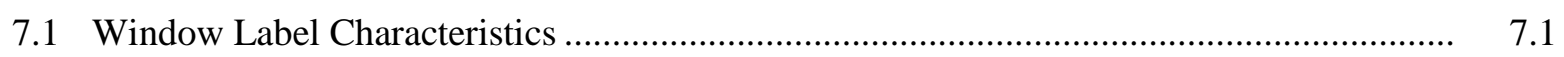

8.0 Create a Training Program ….......................................................................................... 8.1

Appendix A - Software and Testing Equipment for Building Envelope Energy Performance
Laboratory Setup ..................................................................................... A.1 


\section{Figures}

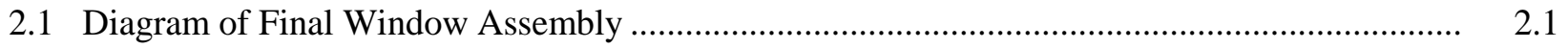

3.1 Board of Director Structure for Australian Window Rating Council ....................................... 3.2

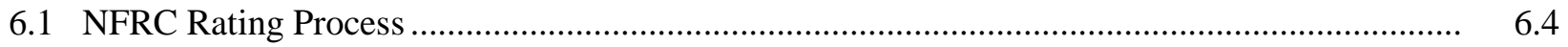

6.2 NFRC Window Energy Rating Label .............................................................................. 6.4

7.1 Chinese Window Energy Label .............................................................................. 7.2

7.2 NRFC Temporary Window Label ….................................................................................

7.3 Window Label from the United Kingdom ...........................................................................

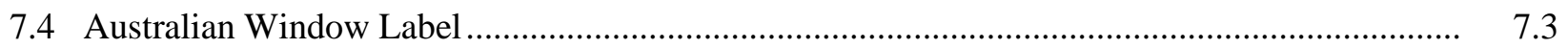

7.5 National Accreditation and Management Institute Label for Windows Manufacturers ............... 7.3

7.6 Window and Door Manufacturers Association Label for Windows Manufacturers ................... 7.3

7.7 Australian Window Association Label ................................................................................... 


\subsection{Background}

The Asia-Pacific Economic Cooperation, or APEC, is the premier forum for facilitating economic growth, cooperation, trade and investment in the Asia-Pacific region. In Sydney, Australia, in September 2007, APEC leaders agreed to an APEC-wide regional goal of reducing energy intensity by at least 25 percent by 2030. They encouraged all APEC economies to aspire to meet this goal while setting individual targets and action plans to improve energy efficiency, which reflected the individual circumstances of different economies.

More recently, in June 2010 at the Ninth APEC Energy Ministers Meeting (EMM9) in Fukui, Japan, the APEC Energy Ministers released the "Fukui Declaration on Low Carbon Paths to Energy Security: Cooperative Energy Solutions for a Sustainable APEC."2 This important policy document stated:

"Energy-efficient buildings and appliances are key to a sustainable future since the building sector accounts for two-fifths of energy use in the region. Net Zero Energy

Buildings are being developed using energy-efficient appliances, components and systems. Trade and investment in energy-efficient appliances can be encouraged through more harmonized standards and testing methods. We are therefore launching a Collaborative Assessment of Standards and Testing (CAST) for such appliances."

This document was prepared as a follow-up action item of two planned workshops on Building Energy Codes and Labeling. These workshops are part of Phase 2 of the APEC project entitled Cooperative Energy Efficiency Design for Sustainability (CEEDS). This document addresses the testing and certification of building products and equipment to support building energy codes, focusing specifically on energy-efficient pre- and post-fabricated windows.

The first Phase 2 workshop was held in Bangkok, Thailand, on 8-10 September 2010. A second workshop, held in early 2011, was hosted by Hong Kong, China, and co-hosted by Japan. This report also includes relevant follow-up action items from the Hong Kong workshop.

\footnotetext{
${ }^{2}$ The text of this statement is at http://www.apec.org/apec/ministerial_statements/sectoral_ministerial/energy/2010_energy.html.
} 


\subsection{Introduction}

This report sets forth a proposed structure for an (APEC Region) economy to establish a rating program for energy-efficient residential and commercial windows. In the context of this document, efficient windows would be windows made with an insulating glass unit (IGU) and an efficient frame assembly. The minimum efficiency metric (or thermal performance) for these windows is not quantified in this document and would generally be established by a governmental agency or recognized code agency, based on a market analysis and an energy savings target.

Pre-fabricated (factory assembled) windows are used primarily in the residential (housing) sector (including low-rise multifamily) and for commercial applications in "punch-out" openings. These windows consist of the IGU and frame assembled in a factory and shipped to the installation site ready to be installed.

Post-fabricated (site assembled) window systems are primarily in the non-residential (commercial) sector and where the IGU and frame are produced by different manufactures and sent to site for assembling. The IGU and related components are typically installed onsite by a skilled assembler.

Figure 2.1 shows a diagram of a typical final window assembly (pre- or post-fabricated).

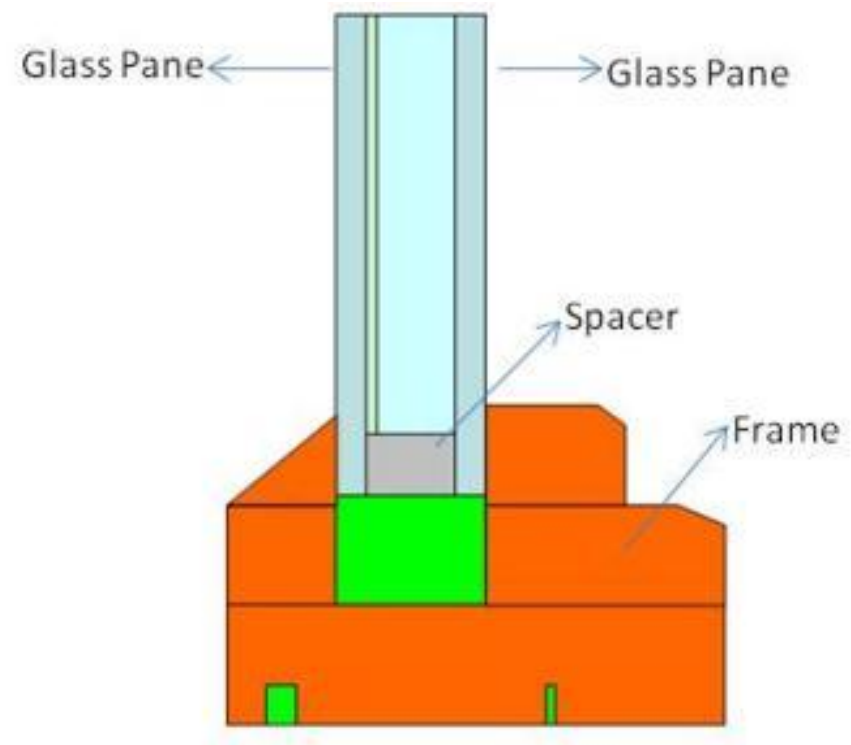

Figure 2.1. Diagram of Final Window Assembly

A window is a complex system. It contains various types of glazings, ${ }^{3}$ characteristics, and sizes. More than one pane of glass is required to ensure that a finished window is energy-efficient. The panes of glass in an IGU are separated by a component called a spacer, which also acts to seal any gas between the panes; gases with low thermal conductivity may be used to provide additional insulation. Each pane is held within a sash and the multiple sashes are themselves held within the entire window frame. Sash and

\footnotetext{
${ }^{3}$ Glazing includes clear and tinted float glass, tempered glass, and laminated glass as well as a variety of coated glasses.
} 
frame materials vary depending on the need. Wood, vinyl, and fiberglass are used commonly for aesthetic features and for energy efficiency, while metal and composite (metal clad) frames are selected for efficiency and structural strength. Specifiers choose thermally broken ${ }^{4}$ metal frames or vinyl/ fiberglass frames with reinforcements for high-rise buildings due to structural strength requirements.

Numerous smaller components (such as balancers, rails, latches, hinges, and weather stripping) complete a window. Their thermal effects, however, are negligible unless they are continuous and/or have significant thermal bridging effects. Therefore, it is important that a simulation tool and testing programs account for all of the possible combinations of materials, properties of those materials, and the assembly that make up the final window. Purchasers then know that they are getting a window product that meets their requirements, performing consistently from window to window as well as from manufacturer to manufacturer.

Although testing, rating, certification, and labeling can be performed by the IGU and window manufacturers themselves (self-certification), these functions are generally best undertaken by independent third-party organizations to maintain credibility and ensure consistency. This model has been employed in North America and other countries that have adopted windows testing programs as well as codes and standards for efficient windows. Independent and certified third-party services rate and label a complete window product sold to consumers. ${ }^{5}$

\footnotetext{
${ }^{4}$ Thermally broken means that a less conductive material is used between panes of glass to reduce the conductive thermal energy from passing through the glass.

${ }^{5}$ As of July 1, 2010, the U.S.-based National Fenestration Rating Council (NFRC) began enforcing the requirement for IG certification by a listed, third-party certification program for all insulating glass units used in products that are authorized for NFRC certification and labeled in accordance with the NFRC 700, "Product Certification Program (PCP)."
} 


\subsection{Requirements}

The following recommended requirements will help establish a comprehensive and effective Rating Program; a detailed description of each is given below.

1. Establish an overarching governing body to oversee a windows simulation/testing, rating, certification and labeling infrastructure;

2. Establish criteria for the windows and component testing and the attributes recorded on the label;

3. Ensure that the manufacturers and site-assembled windows are of consistent quality and meet the ratings standards;

4. Create a labeling process and a label that is affixed to the window; and

5. Ensure proper windows installation through a training program.

\subsection{Establish a Governing Body}

Establish a governing body to oversee and manage the rating program. An example of a governing body structure from Australia is given in Figure 3.1. The governing body should be made up of a collection of manufacturers, suppliers, testing laboratories, and advocacy groups including consumer interests, governmental organizations and educational institutions. The governing body should have a Board of Directors and administrative office (paid staff) to manage the day-to-day operations of the governing body. It is important that the Board of Directors has a balanced and representative mix of all types of participants so consumers and every aspect of the industry have input. The governing body should hold periodic meetings to discuss issues related to the rating program and create voluntary task groups to work on technical and certification issues on behalf of the ratings organization. One of the primary roles of the governing body is to develop policies and manage a uniform rating system for the certification and labeling of windows products, and maintain a database of all certified products for the public to access.

The executive office should be comprised of staff members who will be responsible for executing: 1) the Board of Directors' policy; 2) financials and accounting; and 3) technical and quality control. Figure 3.1 is an example diagram of a Board of Directors' structure as adopted by the Australian Window Rating Council. 


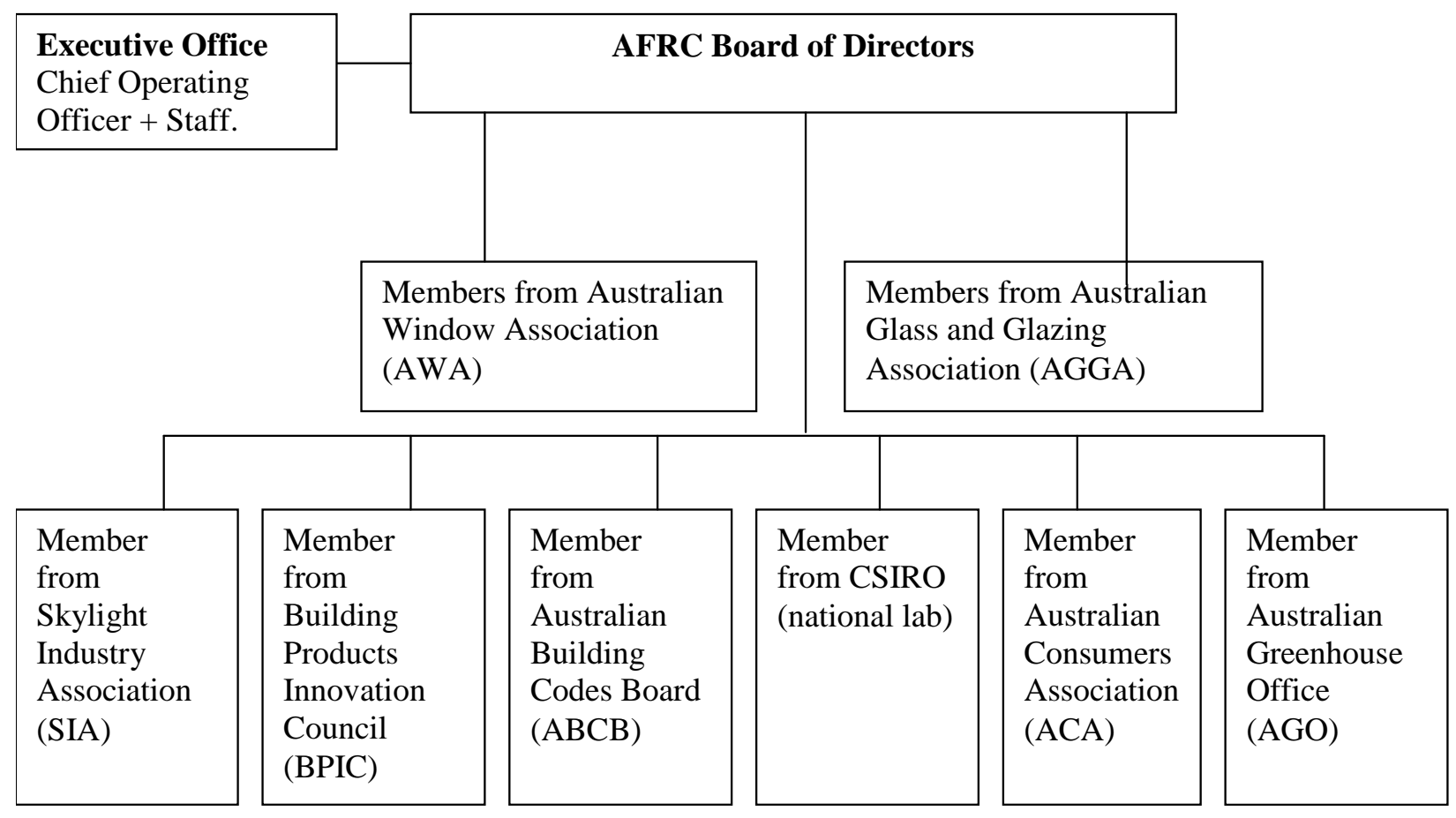

Figure 3.1. Board of Director Structure for Australian Window Rating Council (AFRC)

\subsection{Establish Performance Metrics}

Establish mandatory, minimum window products performance metrics, as well as a testing/rating system and a labeling procedure to display those metrics to the consumer. ${ }^{6}$

From an energy perspective, the most important performance metrics for a window are:

- U-factor - a measure of the rate at which heat is transferred through the window system, which quantifies the overall thermal performance of the window.

- Solar Heat Gain Coefficient (SHGC) - a measure of the amount of incident solar radiation through a window and thus how well the window blocks heat from the sun.

- Air Leakage (AL) -outside air entering the interior of a building through cracks in the window system, infiltration causing increase in cooling load or heating load.

Other important metrics that have an indirect impact on energy use in a building and thus are important from a consumer standpoint include:

- Visible Transmittance (VT) - the measure of the amount of visible light transmitted through the glass. As the Solar Heat Gain Coefficient decreases, the VT of the glass is also reduced due to tints and coatings. A balance needs to be preserved to minimize the use of artificial lighting.

\footnotetext{
${ }^{6}$ For a definition of these attributes, see http://www.nfrc.org/documents/NFRC-600-2010E1A1.pdf.
} 
- Condensation Resistance (CR) - a measure of the resistance of the window to condensation. The resistance to the formation of condensation on glass is important because condensation affects the long-term performance of the window.

\subsection{Establish Testing Laboratories and Certifying Agencies}

Establish accredited simulation and testing laboratories and certified inspection and certifying agencies located within the private sector and ensure they are independent of each other and the manufacturing industry. Ideally, there would be multiple certifying organizations including:

- Accredited simulation and testing laboratories to determine the performance of varying window assembly designs through the use of simulation software and physical testing apparatus;

- Certified inspection and certifying agencies to determine compliance/non-compliance of windows products according to the performance metrics established by the governing body; and

- Agencies that periodically inspect the manufacturing facilities to certify that the windows manufactured continue to meet the performance metrics to which tested. This function is typically performed by a certified inspection agency.

The certifying agency would be licensed and recognized by the governing body as certified and would be given the authority to provide manufacturers with the labels. The certifying organizations would also provide the governing body with the results of the performance testing and the in-plant inspections. The governing body's responsibility would be to verify that the certifying organization conducted the review and inspections appropriately and to make a list of all rated products available to the public.

\subsection{Create a Labeling Process}

Create a labeling process and label for every new window sold or distributed by window manufacturers that is affixed to each window prior to the window being offered for sale to consumers. The label would indicate the energy performance and other selected metrics of the windows and would contain the results of the mandatory performance ratings established by the governing body. Additional performance ratings information for any optional energy-related indices recommended by the governing body would also be included on this label at the discretion of the manufacturer. The information on this label, including any optional rating performance whether or not it appears on the label, would also be included in a windows products public database maintained by the governing body. A distinct/clear portion of this label would also contain a certification that the manufacturer conforms to the on-site plant inspection requirements.

\subsection{Ensure Proper Window Installation}

The proper attachment of the window to the structure is critical to the overall performance of the window. It is also important to the installer of the window to minimize call-backs and to the building occupant/owner for overall product and performance satisfaction. The governing body would recognize the accredited third-party organizations to perform training of the installers. These organizations notify 
the governing body when training has been completed, whereupon the governing body gives accreditation to the trained individual. Upon accreditation, the governing body provides a public list of all individuals who have successfully completed the training.

Each of these five requirements is discussed in more detail in the balance of this report. 


\subsection{Establish a Governing Body}

Establishing a governing body for the windows industry is the first step that should be taken in a process to develop a viable windows testing, rating and certification program. This governing body should be independent (preferably a not-for-profit), and all duties, responsibilities, and elections should be completely voluntary. The only paid staff would be those necessary to carry out administrative duties necessary to maintain the viability of the governing body.

The governing body should initially form a Board of Directors (Board) and elect a chair to oversee the Board. The Board should be made up of representatives from government, industry, academia and consumer interest with a knowledge and practical experience of the buildings and windows industry. Windows manufacturers and interest groups should be considered for the Board; but they should not make up a majority of the membership in order to avoid a possible conflict of interest in the setting of testing, rating and certifications requirements.

\subsection{Board Responsibilities}

The responsibilities of the Board could include but are not limited to:

- Propose the initial scope and requirements for simulation, testing and certification of windows products for the governing body to consider. This would include the requirements for accreditation of a private-sector laboratory to become accredited to undertake simulation and testing of windows products, and certifying inspection agencies to review and verify performance matrix on the labeled product. Future scope and requirements may be generated by the governing body membership depending on the bylaws;

- Oversee members' meetings and establish rules of order for these meetings;

- Vote and make decisions on matters that are not within the jurisdiction of the governing body (to be decided by the governing body);

- Create and maintain the public database of rated windows;

- Create membership committees with responsibilities for oversight in areas such as testing protocols, certification, accreditation, simulation/modeling, labeling, materials, training, etc. These committees would oversee all activities within their topical area and would be authorized to form subcommittees when the subject area becomes too large;

- Establish the mechanism for election of Board members and Board chair and terms of service;

- Establish a "government relations" group to be the prime interface with the federal government and other international institutions involved in actions that regulate, test or certify windows components, windows products, and windows and IGU manufacturing. 


\subsection{Governing Body Responsibilities}

The responsibilities of the governing body (the membership of this organization) could include but not be limited to:

- Meet the requirements for membership as established by the Board and bylaws.

- Set up dues to support the Board and the activities of the organization.

- Serve on committees as required.

- Establish a program for simulation and testing of windows products by accrediting and licensing the private-sector laboratories.

- Establish a program for quality assurance and certification of private-sector inspectors of window manufacturers who will ensure that manufactured products are certified.

- Make recommendations and oversee (through subcommittees) governing body-funded research and development activities.

- Establish compliance assurance program. 


\subsection{Establish Mandatory/Minimum Performance Rating and Certification Criteria}

One of the first actions of the Board is to recommend to the governing body the minimum performance rating and certification attributes for both the insulating glass unit (IGU) and the windows products. At a minimum, these attributes and the minimum or maximum levels at which they are set according to government requirements (e.g., codes and standards) should ensure that windows provide both a high level of cost-effective thermal performance (that is, they reduce heat transfer through the window) and are satisfactory to the consumer at a price consumers will pay.

In addition, the testing and certification process should result in:

1. An IGU used in the window that is durable with a long-lasting seal and maintains a performance level within an acceptable range over the life of the window;

2. The production process of the IGU being certified to follow certain specific quality control and recordkeeping requirements;

3. The finished window product meets - at a minimum - thermal (energy) performance characteristics plus other selected attributes (with identified metrics of those attributes) important to the consumer and consumer comfort;

4. The manufacturing facility being certified to produce windows consistently meeting the certified performance characteristics and maintain quality control.

\subsection{Selecting Window Product Attributes for Performance Rating and Certification}

The following are issues that should be considered when selecting the attributes.

- The selected attributes should be those that the window industry is familiar with and for which there are industry-accepted simulation and testing protocols developed and test equipment available.

- Which attributes will be mandatory (require simulation, testing and reporting) and which attributes will be optional?

- There are window attributes other than energy- or thermal-related attributes that are important. These include but are not limited to:

- The structural performance rating of a window is a measure of the wind load (air pressure) a window can resist before failing. This attribute is often determined by building codes requirements. The higher the structural performance rating, the more wind load a window can resist.

- The water infiltration performance rating of a window is a measure of the resistance, under air pressure, a window can resist before failing. This attribute is often determined by building codes requirements. The higher the water infiltration performance rating, the more the window can resist water leaks due to rain.

- The acoustical performance rating that measures the amount of sound transmission through a window. This may be important for blocking noise from coming through a window. 
- The security performance rating that measures the ability of a window to resist different types of forces such as fire, hurled objects, and forced entry.

- The impact resistance of the window glass from a hurled object. That is, can the glass in the window resist penetration and/or shattering and can the window unit (i.e., the sash) remain intact? This may be an important attribute in areas commonly experiencing periodic high winds, tornados, cyclones or hurricanes.

- How long can the test results be used for labeling/certification and thus how often does a manufacturer need to retest and recertify windows products?

- What changes in a windows product can be made without the need for retesting? That is, would the addition of a new frame color, the change in the stock number, or change in window product name require retesting of the window?

- Adhering to standardization in the reporting of all attributes (mandatory and optional) including units (e.g., SI), the number of decimal places reported, and where and what order the attributes are listed on a label.

- Are the attributes and the metrics for those attributes appropriate for a country or for certain regions of the economy? For example, a requirement for CR or for a minimum/mandatory CR (established to meet a code or standard) that is set at high number $(>50)$ in a mostly cooling-dominated climate region may not be appropriate. What are the health (mold growth) issues with condensation and thus is this and the possible liability related to health an overriding issue?

- It should be straightforward and unambiguous for a testing laboratory to acquire and set up test apparatus, to calibrate testing equipment and conduct the tests efficiently across a number of window products (multiple windows types and sizes) from multiple manufacturers.

- What is the cost for testing and certification and how does that impact the price of a window to the consumer? Could that cost be passed along from all windows manufacturers to the consumer? If so, are the costs comparable across all windows manufacturers?

- How much testing/many tests for the attributes selected of the multitude of widows products produced by manufacturers is required vs. using simulation tools to model variations in windows products as an alternative means of assuring the windows meet the selected attributes?

- Are there international standards, experience and examples that can be drawn upon for establishing the attributes, and the testing protocols, and is this experience applicable to the country?

- There is considerable experience in the United States with the National Fenestration Rating Council (NFRC) (www.nfrc.org) as the U.S.-based governing body for the certification and testing for determining the energy performance of windows as well as doors and skylights. Many of the required tests by NFRC rely on following standards or protocols promulgated by the ASTM International (www.astm.org), International Organization for Standardization (ISO) (www.iso.org) and the American National Standards Institute (ANSI) (www.ansi.org).

The actual testing protocol and calibration of the apparatus is set forth in standards promulgated by the ISO and the International Electrotechnical Commission (www.iec.ch). Each of these organizations will be referred to in the discussion below. 


\subsection{Establish Simulation, Testing and Certification Organizations}

Simulation, testing and certification laboratories should be set up in the private sector to be the independent and unbiased laboratory for the windows industry. In addition, a manufacturer site (factory) accreditation program should also be established to ensure that the sample of windows that meet the laboratory testing and certification are produced in quantity in the factory in a consistent manner with adequate and documented quality control.

The simulation and testing laboratories would be established to independently (from the manufacturers) test windows products supplied by the windows industry to the protocols established by the governing body for the certification attributes that are likewise established by the governing body. The laboratory should be capable of simulating windows performance from inputs of windows components and results of the testing of similar windows from a manufacturer. Simulation is an important component of testing given that not all windows of a type and product line are identical with identical performance metrics. U-factor can be simulated (calculated) with a high degree of confidence since there are multiple size (dimensions) variations and both corresponding window U-factor and other energy performance characteristics of different sizes for the same product lines. Multiple simulation configurations provide additional assurances of compliance.

\subsection{Testing and Certification of Windows Products}

A windows manufacturer would provide a sample of a windows product to be simulated, tested and certified by an accredited testing laboratory in order for that product to be labeled with the certification label. The sample size (number of windows) of the window product to be simulated and then tested before being certified would be established by the protocols set by the governing body.

Other factors to be considered in the simulation, testing and certification of windows products include:

- Is a process in place to assure the governing body and testing laboratory that the window product samples submitted for testing and/or simulation are production-line units (e.g., pulled off the production line rather than custom or hand-made)?

- How long is the certification valid? Should the manufacturers be required to certify a windows product periodically even though the product has not changed (e.g., same brand/model number)?

- What kind of structural or other changes to a previously certified windows product would allow recertification using only a simulation rather than a physical testing and recertification? What structure or other changes to a certified window would require physical testing and recertification?

- How do the governing body and the manufacturer handle a situation when a certification for a window product is near expiring, and recertification is in progress, but will not be completed until after the current certification is expired?

- What is the right mix or sample of products (window type/model) that should be tested from each plant? 
- Should a windows product (window type/model) sample be tested from every plant of that manufacturer making that product? What would be the course of action should the same product (window type/model) testing give significantly different values? An example sampling protocol is to require the manufacturer to submit 15 specimens of a particular window product for testing from which ten are randomly chosen by the testing laboratory. From these ten test results the highest two and lowest two results are discarded, and an average is drawn from the remaining six.

- Should it be a requirement that the plant or manufacturing facility producing the windows products submitted for testing be a pre-certified and pre-accredited plant (see 6.2 below)?

\subsection{Attributes of the Testing/Certification Laboratory}

The attributes and operation of a testing/certification laboratory include but are not limited to:

- Certification and accreditation and re-certification and re-accreditation (as specified) by the governing body as a testing laboratory for windows products;

- Pay fees (if any) to maintain certification and accreditation as an approved testing laboratory;

- Compliance with - and testing for - product rating or certification in accordance with the approved standard or procedures set forth by the governing body as well as international organizations such as the International Organization for Standards ISO/IEC 17025, General Requirements for the Competence of Testing and Calibration Laboratories;

- Following and documenting prescribed protocols for equipment calibration;

- Participating in periodic training workshops;

- Participating in "round-robin" testing of windows products with other nationally and internationally certified and accredited laboratories.

ISO/IEC 17025:2005 specifies the general/generic requirements for the competence to carry out tests and/or calibrations, including sampling. It covers testing and calibration performed using standard methods, non-standard methods, and laboratory-developed methods. It is applicable to all organizations performing tests and/or calibrations. These include, for example, first-, second- and third-party laboratories, and laboratories where testing and/or calibration forms part of inspection and product certification.

\subsubsection{Equipment for Laboratory Testing}

The type of equipment used in a testing laboratory and a brief description of the equipment include (more details are provided in Appendix A):

- A test chamber (also known as a "hot box") for measuring thermal transmittance (U-factor) a thermal performance matrix of windows. A hot box can be either a "calibrated," "guarded," or "wall and edge guarded" type. The most common type is calibrated that has two main chambers, warm side chamber (also known as indoor or room chamber) and cold side chamber (also known as outdoor or environmental chamber). In between the chambers is a surround panel, which separates two chambers at different temperatures and air movement regimes. Both chambers are made of highly insulating materials with very thick walls, so that the loss to the surrounding space in which a hot box 
is situated is kept at the minimum. This is very important since the total (integrated) energy flow from warm to cold side is being measured, and any extraneous losses need to be kept at a minimum. The ISO has a hot box testing standard: ISO 12567-1:2010 Thermal performance of windows and doors - Determination of thermal transmittance by the hot-box method-Part 1: Complete windows, doors, and a Thermal performance of windows, doors and shading devices - Detailed calculations (ISO 15099:2003). In addition to standard methods, technical reports and guidelines are being developed to guide and help laboratory personnel execute tests properly. This same chamber can be used to test the condensation resistance of windows by simulating interior and exterior temperatures and humidity.

- A test chamber (also known as a "solar calorimeter") for measuring solar heat gain coefficient (SHGC) a performance matrix of windows. NFRC-201 test method provides design requirements, guidelines and specifies calibration procedures required for the measurement of the (SHGC of window systems and glazing systems installed in a solar calorimeter (hot box). This test method applies to all window systems, glazed apertures in buildings intended for the controlled admission of solar radiation. This includes windows, glazed doors, translucent panels, skylights, and glazing systems incorporating integral or attached shading devices such as insect screens, drapes, shades, and blinds.

- A test chamber to measure air leakage of windows measuring air infiltration rate (AL-value) a performance matrix of windows. This chamber simulates a given set of natural environmental conditions and thus would need to apply a vacuum on one side of the window to simulate wind blowing perpendicularly to the window and flow meters on the other side of the window to measure air flow through the window frame. ISO 6613:1980 Windows and door height windows - Air permeability test, specifies this test.

\subsection{Pre-Fabricated Certification of Windows-The Process}

The manufacturer wanting to obtain certification for their window product are required to simulate all options, including glazing, spacers and frame, within a product line. Simulation has to be performed by an accredited testing laboratory. Each modeled option within a product line is termed as an individual option. From the matrix of the individual options, a base line product is identified. Base line product is the individual product within a product line, selected for validation testing. It is generally a best performing product is selected as it has the worst error bias attached to it. Therefore, if this product would validate via testing then rest of the products would validate. Figure 6.1 illustrates this process for the NFRC. 


\section{NFRC "Rating Process"}

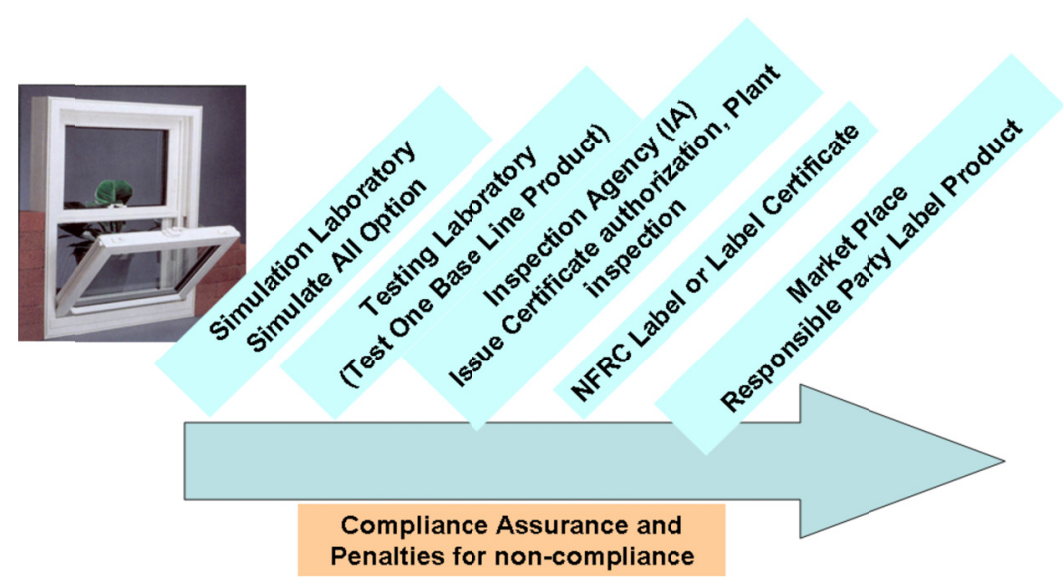

Figure 6.1. NFRC Rating Process

The simulation and the physical test report are sent independently to a licensed certification agency (IA). The licensed IA is responsible for verifying the validation of the simulation and the testing data. Upon meeting the validation requirements, the simulated values for all individual options within the product line are entered into a database. An in-plant inspection of the manufacturer's facility would be conducted by the IA to verify that the product is made as was simulated for determining the performance rating. Upon carrying out the quality control inspection and verifying all compliance, the IA would issue a Certification Authorization Report, "CAR," which list the values of energy performance rating of all individual products within a product line. Upon receipt of the CAR, the manufacturer is authorized to label the representative products within the simulated product line. Only the labeled window product is considered as certified products in the market place. Values of all certified products are listed in the certified products directory and can be viewed live on the NFRC website (http://search.nfrc.org/), allowing consumers, code officials and others to verify the claims. If the label is not representative of the product performance rating, and the values are falsified, through the compliance assurance program legal action can be taken against the responsible party. Figure 6.2 shows an example of a NFRC window label.

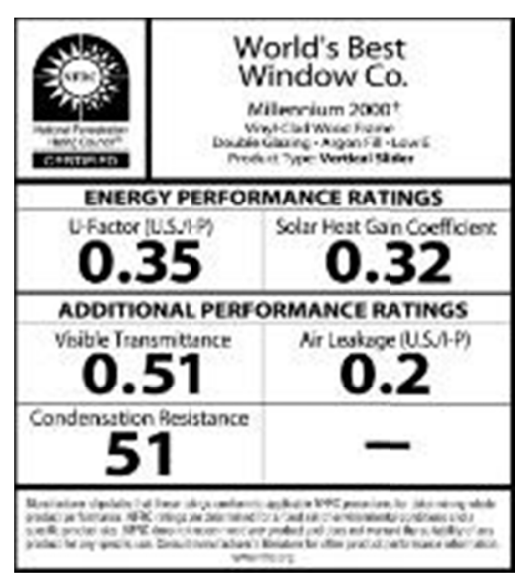

Figure 6.2. NFRC Window Energy Rating Label (Used in U.S., Canada, Australia) 


\subsection{Post-Fabricated Certification of Windows-The Process}

A post fabricated windows rating program should provide consistent and reliable energy performance ratings for code enforcement purposes. It needs to address issues associated with preliminary project bidding and/or design needs, project customization, or the need for size-specific product ratings.

The NFRC has develop a rating program called the component modeling program (CMA) which uses the component modeling approach to derive the overall thermal performance of post-fabricated window unit to determine the rating indices.

\subsubsection{CMA Procedure: How It Works}

The scope of the CMA program is to develop a new nonresidential certification and rating procedure for window products that will yield accurate energy performance data for use in code compliance and for meaningful building energy analysis. The certification and rating program is designed to be credible, simple, cost effective, fair, uniform and useful.

Component performance data are used for obtaining overall product performance employing NFRC's CMA Software Tool (CMAST). The three primary components used are:

- Glazing: Glazing optical spectral and thermal data from the International Glazing Database (IGDB);

- Frame cross-sections: Thermal performance data of frame cross-sections; and

- Spacer: $\mathrm{K}_{\mathrm{eff}}$ (overall effective conductivity) of spacer component geometry and materials.

The CMA program allows different segments of the window industry to obtain standardized energy performance ratings for window components and component systems including glass, spacers and frames. These systems will reside in electronic libraries that will be easily accessed by those who wish to determine and/or obtain NFRC energy performance ratings (U-factor, SHGC, VT) for entire window, storefront and curtain wall systems.

CMA outputs will include a standardized bidding tool for building specifications, exporting capabilities for whole building energy analyses and an NFRC label certificate for code enforcement and specification confirmation.

\subsection{Inspection of Windows Manufacturing Plants}

The certification of the windows manufacturing facilities themselves is essential for maintaining windows product quality as they are produced in quantity. Given the laboratory testing and certification is done on a small sample of windows from each product line (and assumed to be a sample from the production line), this certification process is vital given the large numbers of windows produced for the market that are never laboratory tested but receive the certification label.

This certification would include testing of individual components (e.g., spacers, hinges) that go into a window to determine that the components pass their own individual performance test. This certification also includes a "shop floor" inspection by trained and qualified inspectors to make sure that the production line units are built to the same specifications as the sample was tested by the certification 
laboratory. In addition, this certification should check randomly (on an annual basis) the manufacturing plant production lines, inventory, and quality control records.

The governing body should establish a training program and protocols for these inspectors. The reports by the qualified inspectors should be provided to the governing body and results (pass/fail/ no inspection) posted on a database of windows manufacturers.

\subsection{Certification of an Integrated Glass Unit Manufacturing Plant}

The governing body should also set forth requirements for a certification program for the manufacturer of the IGU. As with the testing and certification of the windows products, an independent third-party organization or agency should likewise carry out the certification process under an agreement (or license) with the governing body and using the guidelines set forth by the governing body. The IGU manufacturing certification should be designed primarily for quality control, that is, to ensure that the IGUs are manufactured consistently to established and recognized manufacturing standards. Like the windows themselves, there are a myriad of different types of IGUs with a wide range of performance (primarily the IGU U-factor) expectations. It is important that the IGUs used by the window manufacturers be of consistent quality and that the U-factors for IGUs remain consistent through the expected life of the window product.

The following are the requirements of an IGU certification program conducted by an accredited certification organization or agency:

- In-plant inspection of the manufacturing process.

- Requirement for specific process/production documentation and quality management record keeping.

- Assuring that the seal between window glass sheets is viable and durable and that any gas used to fill the cavity between the glass sheets will remain over the lifetime of the window.

- This may require passing tests prescribed by testing organizations such as ASTM E2190-08 "Standard Specification for Insulating Glass Unit Performance and Evaluation" that includes testing for the durability of the seal.

- This may require a quality control program to ensure that the spacers (used between the glass sheets) are stored and handled properly, and are free from any contamination and/or outgassing (including moisture).

- Assuring that the IGU is free from streaks, spots or other contamination on the inside surfaces of double-pane or triple-pane glass.

- On the shop floor, this may require manufacturing conditions approaching a clean room environment and careful attention to the glass washer water chemistry/temperature and air that is free from particles and contaminants.

- Submittal of inspection information into a certified products database maintained by the governing body. 


\subsection{Create a Labeling Process and Labels}

Visible certification showing that a credible laboratory verified the product met government established attributes provides purchasers of windows with important assurances about their investment in energy-efficient products. This label will also inform the consumer that the window manufacturer's factory/shop floor has been certified by an independent and qualified organization. There should only be a single label containing all the required certifications affixed to the window.

The governing body should create a consumer-friendly, easily identifiable and legible label that will be affixed to each window product prior to shipping and easily removed only after the window is installed. In addition, the governing body should recommend a permanent label that cannot be removed, is resistant to weathering and is legible. The permanent label could be stamped or etched into the window frame.

Both labels should contain the manufacturer, model number and the results of the tests for the selected attributes in units familiar to the consumer. The permanent label should follow a code (letters and numbers) that indicates the standard to which the product was tested, a name (to provide traceability) of the manufacturing facility, the structural performance level achieved, the series or model name of the product and other information pertinent to that product. This label information can be cross-referenced with the certified products database kept by the governing body and third-party certifying entity.

\subsection{Window Label Characteristics}

Characteristics of the temporary (removable) label include:

- Appearance of an official (registered) logo from the governing body certifying the window product and the web address of the governing body;

- Disclaimers about the window label/labeling process from the governing body;

- Appearance of all the test results (ratings) of the attributes required by the governing body and - as an option - any test results that are considered optional by the governing body;

- Date the product received the certification(s).

The label information should match the data in the certified products database maintained by the governing body. Note that a certification label does not mean the window system is energy-efficient. Rather, it provides information about energy performance and other attributes that consumers can then use to determine if the product is efficient for their region or situation and to compare the performance and other attributes of similar windows products with one other. The governing body provides the template for the labels to the manufacturer with guidance on when, where, and how long it is to be affixed. The governing body will formally inform the manufacturer when all tests and certifications have been received. The manufacturer can create and attach the label at that time. Some example labels from the aforementioned, well-established windows rating programs follow.

Examples of window labels from a number of countries are shown in Figures 7.1 through 7.7. 


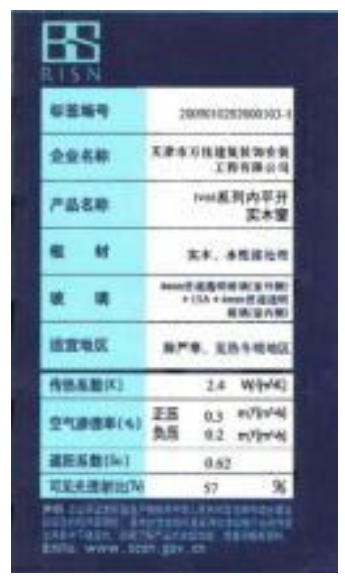

Figure 7.1. Chinese Window Energy Label

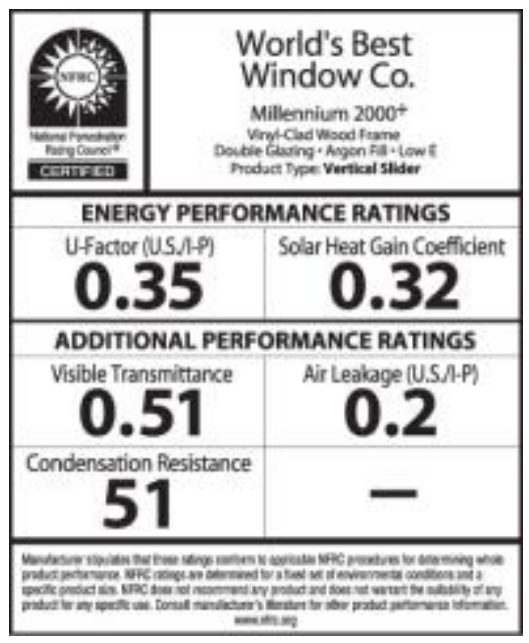

Figure 7.2. NRFC Temporary Window Label

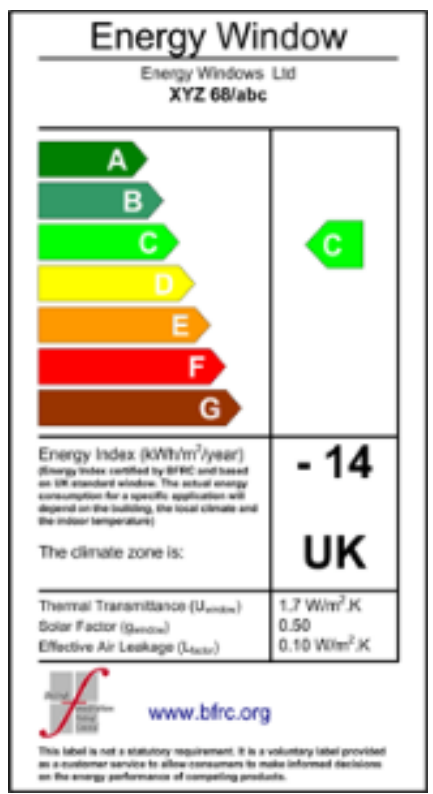

Figure 7.3. Window Label from the United Kingdom 


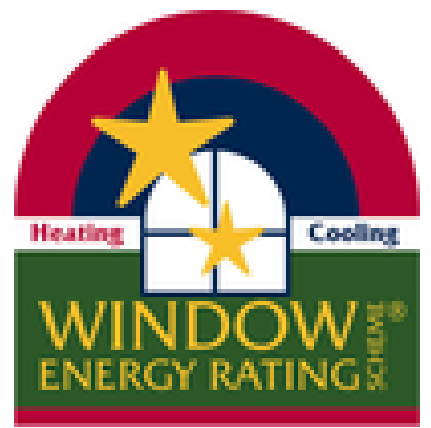

Figure 7.4. Australian Window Label

\begin{tabular}{|c|c|c|c|c|}
\hline ravis & $\begin{array}{l}\text { MANUFACTUAER STIPULATES CONFORMaNCE TO } \\
\text { AAMA/NWWDA 101/I.S.2-97 }\end{array}$ & $\begin{array}{l}\text { CODE: } \\
\text { SPEC: } \\
\text { SEAIES: } \\
\text { MST: }\end{array}$ & $\begin{array}{l}\text { S.019-1 } \\
\text { H.R45 } \\
8500 \\
3850\end{array}$ & $\begin{array}{l}\text { HUD } \\
\text { ACCEPTED } \\
\text { CEATIFICATION } \\
\text { PAOARAM }\end{array}$ \\
\hline
\end{tabular}

Figure 7.5. National Accreditation and Management Institute (NAMI) Label for Windows Manufacturers

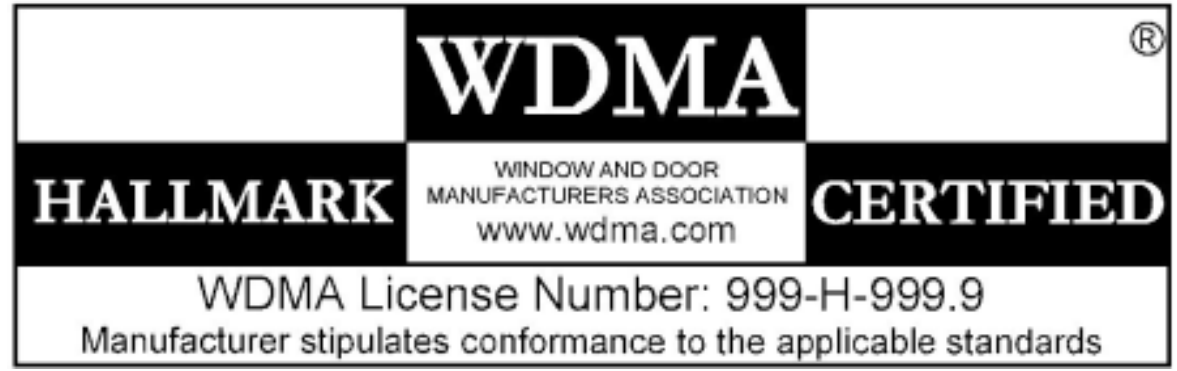

Figure 7.6. Window and Door Manufacturers Association (WDMA) Label for Windows Manufacturers

\begin{tabular}{|l|l|}
\hline AWA This manufacturer certifies that this \\
product was designed to conform \\
with AS2047. The design perfor- \\
mance has been verified by a NATA \\
accredited test laboratory. This
\end{tabular}

Figure 7.7. Australian Window Association Label 


\subsection{Create a Training Program}

The governing body should create a training program using private-sector trainers that will ensure the correct installation of windows in both new and retrofit applications. The training program will be focused primarily on the professional installer industry; however, it could also be modified to train individual homeowners in the proper installation of windows, primarily in a retrofit application. Support for training can come primarily from the window manufacturers since they have a stake in correct installation according to their specifications in order to provide the performance expected by the consumer. Window manufacturers generally provide a warranty for their products, and proper installation will substantially reduce call-backs, which are primarily due to improper installation. The consumer will benefit from a training program by having a properly installed window that delivers both thermally (is efficient) and structurally.

The following are components of a viable training program led by the governing body for window installation:

- Involve the window manufacturers to create the training and incorporate any manufacturer-specific components into the training if feasible;

- Involve window manufacturers in the actual training;

- Partner with the building/building trades industry to incorporate windows installation training into any training that the industry conducts for builders;

- Create a web-based training module to supplement classroom/field training;

- Create an application for a mobile device (such as an iPhone) that demonstrates correct windows installation. 


\section{Appendix A}

\section{Software and Testing Equipment for Building Envelope Energy Performance Laboratory Setup}




\section{Appendix A}

\section{Software and Testing Equipment for Building Envelope Energy Performance Laboratory Setup}

\section{A.1 Simulation Software Program}

\section{A.1.1 WINDOW 5}

WINDOW 5.2 is a publicly available computer program for calculating total window thermal performance indices (i.e., U-values, solar heat gain coefficients, shading coefficients, and visible transmittances). WINDOW 5.2 provides a versatile heat transfer analysis method consistent with the updated rating procedure developed by the National Window Rating Council (NFRC) that is consistent with the ISO 15099 standard. The program can be used to design and develop new products, to assist educators in teaching heat transfer through windows, and to help public officials in developing building energy codes. The example screen below shows the Glass Library, which is used to calculate the insulated glass unit (IGU) results in the WINDOW Glazing System Library for a specific product).

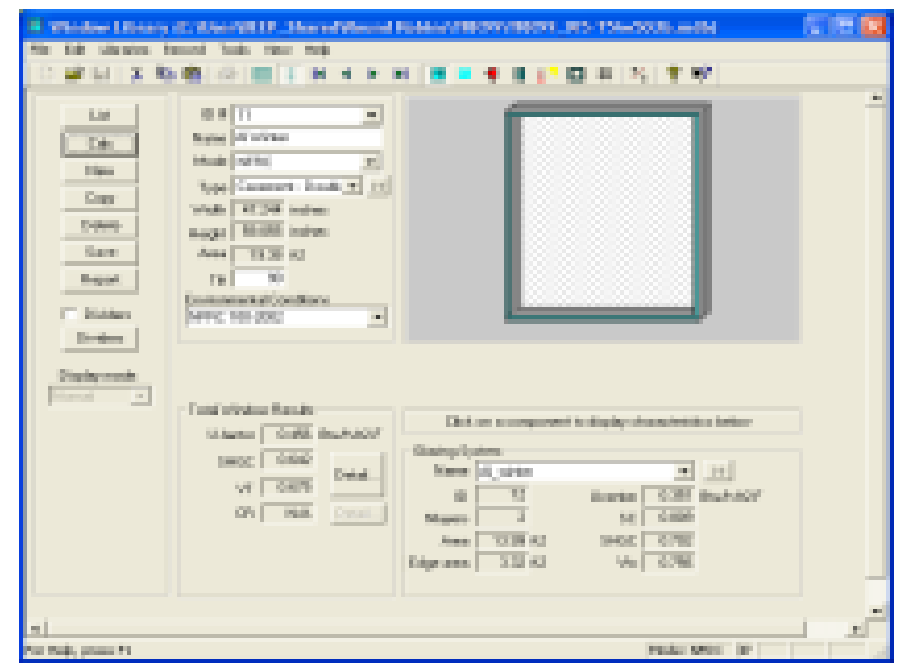

\section{A.1.2 THERM 5}

THERM 5 is a module of the WINDOW +5 program developed by Lawrence Berkeley National Laboratory (LBNL). THERM's results can be used with WINDOW's center-of-glass optical and thermal models to determine total window product U-factors and Solar Heat Gain Coefficients. 


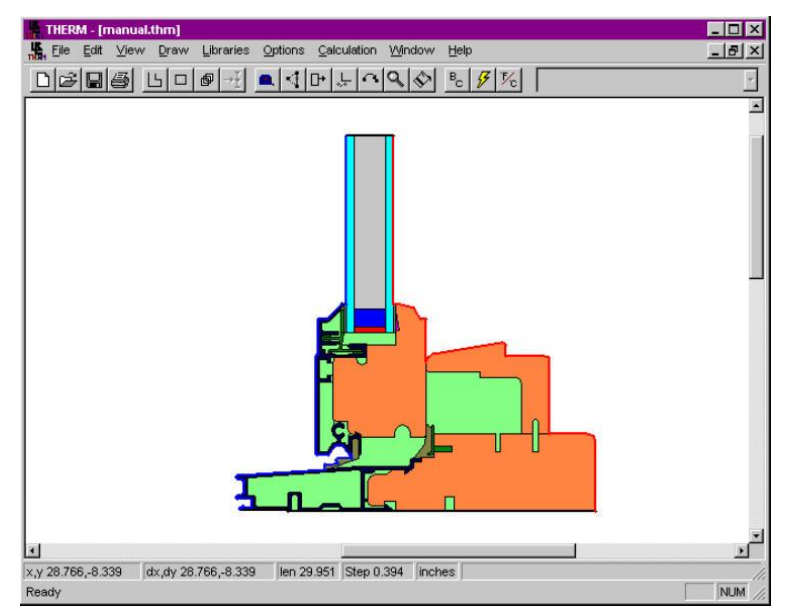

THERM is a state-of-the-art, Microsoft Windows ${ }^{\text {TM }}$-based computer program developed at LBNL for use by building component manufacturers, engineers, educators, students, architects, and others interested in heat transfer. Using THERM, you can model two-dimensional heat-transfer effects in building components such as windows, walls, foundations, roofs, and doors, appliances, and other products where thermal bridges are of concern.

THERM's heat-transfer analysis allows you to evaluate a product's energy efficiency and local temperature patterns, which may relate directly to problems with condensation, moisture damage, and structural integrity. THERM's two-dimensional conduction heat-transfer analysis is based on the finiteelement method, which can model the complicated geometries of building products.

For more information, visit http://windows.lbl.gov/software/default.htm.

\section{A.1.2.1 Reference Documents}

ISO 15099, ISO 9050

\section{A.1.3 EnergyPlus}

EnergyPlus is a whole building energy simulation program that engineers, architects, and researchers use to model energy and water use in buildings. Modeling the performance of a building with EnergyPlus enables building professionals to optimize the building design to use less energy and water. Each version of EnergyPlus is tested extensively before release.

EnergyPlus models heating, cooling, lighting, ventilation, other energy flows, and water use. EnergyPlus includes many innovative simulation capabilities: time-steps less than an hour, modular systems and plant integrated with heat balance-based zone simulation, multizone air flow, thermal comfort, water use, natural ventilation, and photovoltaic systems. EnergyPlus runs in the Windows, Macintosh, and Linux platforms. Free add-ons and other third-party software products are available for use with EnergyPlus. Read a fact sheet on EnergyPlus at the link below. 


\section{A.2 Equipment}

\section{A.2.1 Thermal Transmittance Testing Chamber (Guarded Hot Box)}

This equipment is used for the measurement of the thermal transmittance (U-factor) and thermal resistance (R-Value) of window and building walls assembly/components.

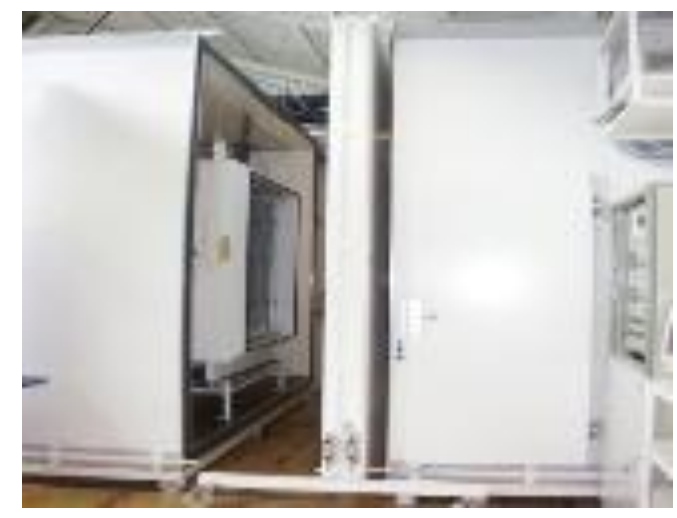

Testing chamber used to measure thermal transmittance, thermal resistance of windows and building assembly components.

The guarded hot box test method is used for establishing the thermal performance of building assemblies when exposed to controlled environmental conditions, (i.e., surface heat transfer coefficients at temperature conditions representative of their use). This test method is used for large homogeneous or non-homogeneous specimens. Smaller flat homogeneous specimens can be tested using the Heat Flow Meter. This test method may be applied to building structures or composite assemblies of building elements for which it is possible to build a representative specimen appropriate for the test apparatus.

\section{A.2.1.1 Components in Guarded Hot Box}

- Room Side Metering Chamber

- Environment Side Room Chamber

- Guard Chamber

- Surround Panel for installing test specimen

\section{A.2.1.2 Room Side Metering Chamber}

- Heater

- Fans to circulate air in the metering room within natural convection flow requirements

- Baffle

- Heaters for Baffle

- Humidity control 
- Temperature controlled ON/OFF switch

- Thermocouple wire, Type T 30 gauge

\section{A.2.1.3 Environment Side Room Chamber}

- Refrigeration System

- Heater

- Fan System to generate required film coefficient

- Thermocouple wire, Type T 30 gauge

- Baffle

\section{A.2.1.4 Guard Chamber}

- Fans to circulate air

- Split system to maintain the required temperature in the guarded area

- Surround Panel

- Foam of at least 4" thick for installation of products

\section{A.2.1.5 Controls}

- PID controller system for control of environmental conditions in the chambers

- Data acquisition System to read thermocouple readings, heat energy, etc.

- Inverter to control environmental chamber fan speed

\section{A.2.1.6 Calibrations}

- Calibration transfer standard

- Thermocouple calibrator

- Computer

- Computer that would be able to hold required controller cards

\section{A.2.1.7 Reference Documents}

ASTM C 1363, C1199, and E1423, NFRC 100 and 102, ISO 8990, ISO 12567

\section{A.2.2 Solar Calorimeter}

This equipment is to be built to specifications and will not be available in the market place. WinBuild, Inc. has a state-of-art design for solar calorimeter construction. 
Solar heat gain property measurements are made using solar calorimeters exposed to solar radiation under clear sky conditions (outdoors) or using artificial solar radiation (indoors). The test sample is illuminated with either direct beam radiation only, or with a direct beam plus diffuse sky and ground reflected radiation.

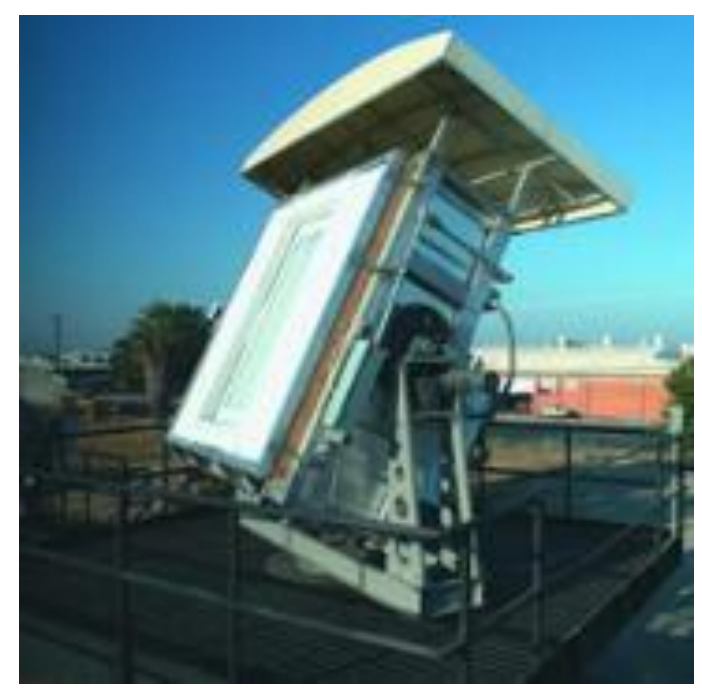

Custom-made solar calorimeter for testing windows.

This test method applies to all window systems, glazed apertures and building envelope components in buildings intended for the controlled admission of solar radiation. This includes windows, glazed doors, translucent panels, skylights, and glazing systems.

\section{A.2.2.1 Components for Indoor Solar Calorimeter}

- Room Side Metering Chamber

- Guard Chamber

- Surround Panel for installing test specimen

- Sun tracking system

\section{A.2.2.2 Equipment}

- Heater

- Fans to circulate air in the metering room within natural convection flow requirements

- Absorbance Plate

- Water flow system to absorb incident and gain solar energy

- Tracking system

- Thermocouple wire, Type T 30 gauge

- Sample Plane Pyranometer: WMO Class 1 instruments to measure the incident irradiance on a plane parallel to the test aperture 
- Horizontal Pyranometer: WMO Class 1 instruments to measure the global horizontal (beam plus diffuse) irradiance

- Wind Velocity meter

- Chiller system

\section{A.2.2.3 Controls}

- PID controller system for control of environmental conditions in the chambers

- Data acquisition system to read thermocouple readings, heat energy, etc.

\section{A.2.2.4 Calibrations}

- Calibration transfer standard

- Thermocouple calibrator

\section{A.2.2.5 Reference Documents}

NFRC 201, ASTM C 1363, C1199, and E1423, NFRC 200, and 300

\section{A.2.3 Spectrophotometer with Integrating Sphere}

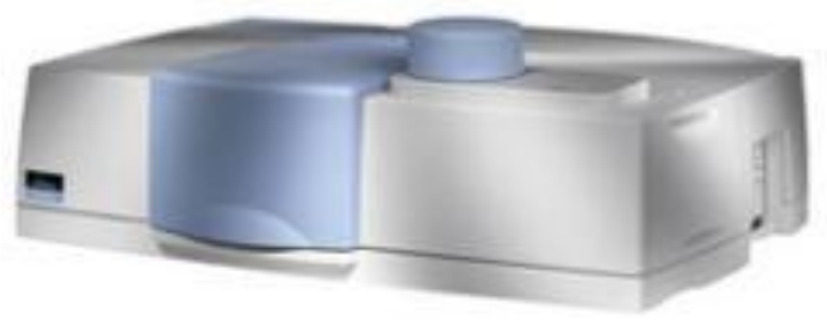

Integrating sphere spectrophotometer.

These Instruments are used for determining the solar optical properties of glazing materials relevant to energy transfer in flat specular glazing materials. The solar absorbance, reflectance, and transmittance of materials are determined using a spectrophotometer and integrating spheres. These data are fundamental for simulation programs WINDOW, THERM, and OPTICS to analyze the glazing and window energy and spectral optical performance.

\section{A.2.3.1 Equipment}

Lambda 1050 and the Optical model FTIR from Perkin Elmer are specially designed for optical and radiometric accuracy. These instruments are modified to meet the testing specification requirements.

\section{A.2.3.2 Reference Documents}

NFRC 300, ASTM E903, LBNL sample and data documentation 


\section{A.2.4 Air Infiltration Water and Structural Testing Chamber}

This equipment is to be built to specifications and will not be available in the market place.

The equipment is used to determine the air-leakage rates, water leakage and provide a structural test of windows, doors and curtain wall.

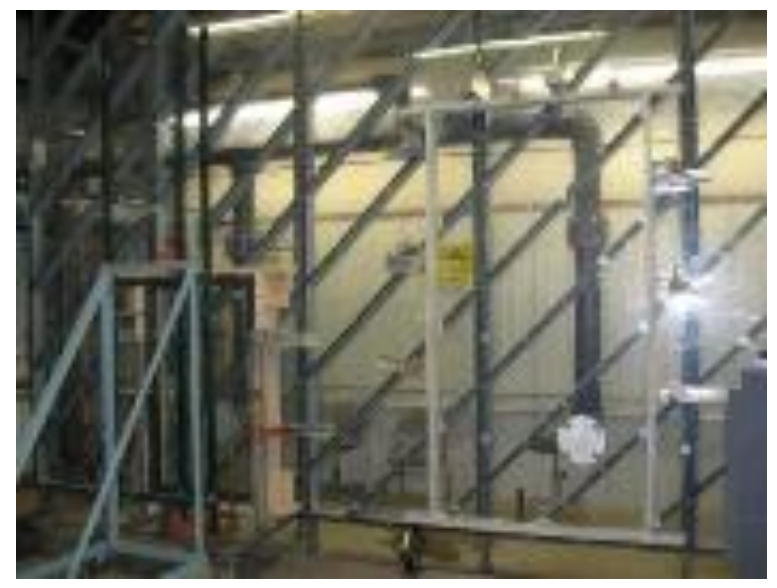

Air leakage and water leakage testing apparatus.

\section{A.2.4.1 Components for the System}

- Fabricated acrylic and steel wall

- Panel for installing test specimen and calibrations

- Air flow system including flow measurement and controls

- Water spray system

- Deflection system

\section{A.2.4.2 Equipment}

- Fabricated acrylic and steel wall - Room Side Metering Chamber

- Blower

- Pressure, mass flow, deflection measurement instruments

- Laminar flow device

- Water spray rack, with specified nozzles

- Reservoir water tank, and water pump

- Temperature and barometric pressure measurement device

- Clamping accessories

- Calibration plates 


\section{A.2.4.3 Controls}

- Data acquisition system to read measurement of pressure readings, flow rate, etc.

- Controls for controlling flow rate and pressure

- Computer

- Lab view software

\section{A.2.4.4 Size}

$12 \mathrm{ft}$ by $12 \mathrm{ft}$

\section{A.2.4.5 Reference Documents}

ASTM E 283, E330, E331, E547,AAMA 101

\section{A.2.5 Sealed Insulating Glazing Units Testing: Structural Testing Chamber}

- E 2188 Standard Test Method for Insulating Glass Unit Performance

- E 2189 Standard Test Method for Testing Resistance to Fogging in Insulating Glass Units

- E 2190 Standard Specification for Insulating Glass Unit Performance and Evaluation

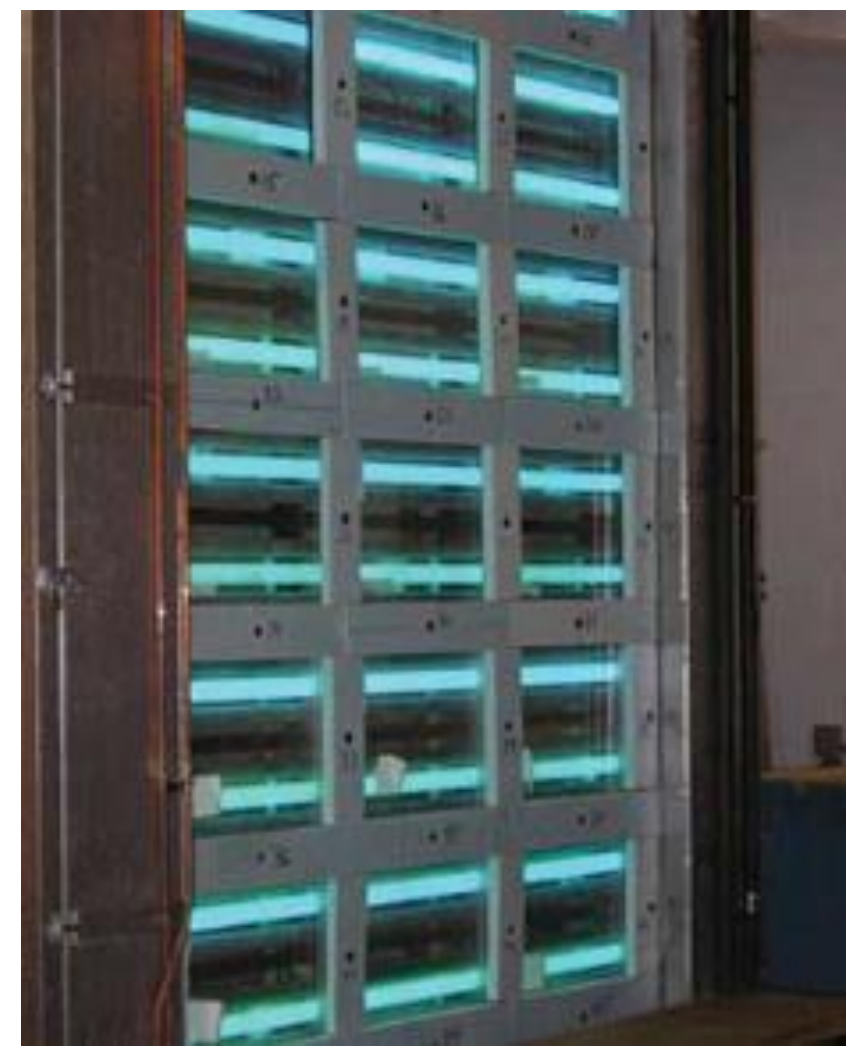

Structural testing chamber simulating weather cycling from hot to cold extremes with moisture added. 
This last referenced standard provides the testing protocol for insulating glass units. There are some minor differences in some of the temperatures used and sample sizes required in the ASTM E 2190 Standard. These differences are mostly attributed to conversions from English to metric units. The main differences can best be described by separating the standard into three parts: the high humidity test, the accelerated weathering test and the volatile fog test.

\section{A.2.5.1 High Humidity Test}

In this test, IGU samples are subjected to high humidity and temperature. The objective is to force moisture into the hermetically sealed cavity of the IGU. All three standards use the same type of box and similar high temperatures. The CGSB 12.8 cycles the units from $22^{\circ} \mathrm{C}$ to $55^{\circ} \mathrm{C}$. E 773 and the ASTM E 2190 test method have no cycling. However, both the ASTM E 2190 and E 773 have 50\% more time in the high-humidity box. Furthermore, CGSB 12.8 uses separate samples for the high humidity test and the accelerated weathering. The ASTM E 2190 and E 773 test require the same samples be used in both high humidity and accelerated weathering.

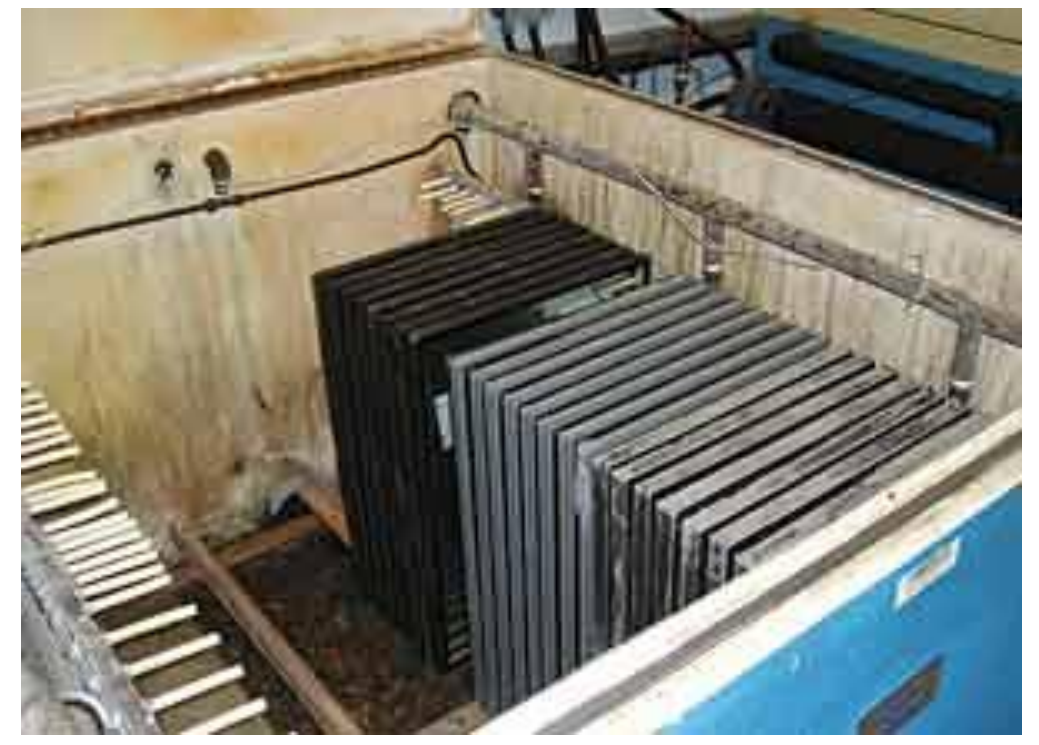

Testing apparatus for humidity and temperature testing of insulating glass units.

\section{A.2.5.2 Accelerated Weather Cycling}

This test is used to simulate weather cycling from hot to cold extremes with moisture added during the hot cycle. The cycling boxes are essentially the same for all three methods. However, both ASTM E 2190 and E 773 have UV radiation during cycling. The CGSB 12.8 test has no UV. As noted previously, ASTM E 2190 and E 773 are required to test the same units in both the high humidity and accelerated weather cycling, while CGSB 12.8 allows separate samples for each test. CGSB 12.8 has more cycles ( 320 versus 252), but the cycles are of shorter duration than ASTM E 2190 and E 773 (63 days versus 53.3 days). The criterion for passing this test is a frost point of $-40^{\circ} \mathrm{C}$ for both ASTM E 2190 and CGSB 12.8. For E 773, the criterion is warmer, $-20^{\circ} \mathrm{C}$. 

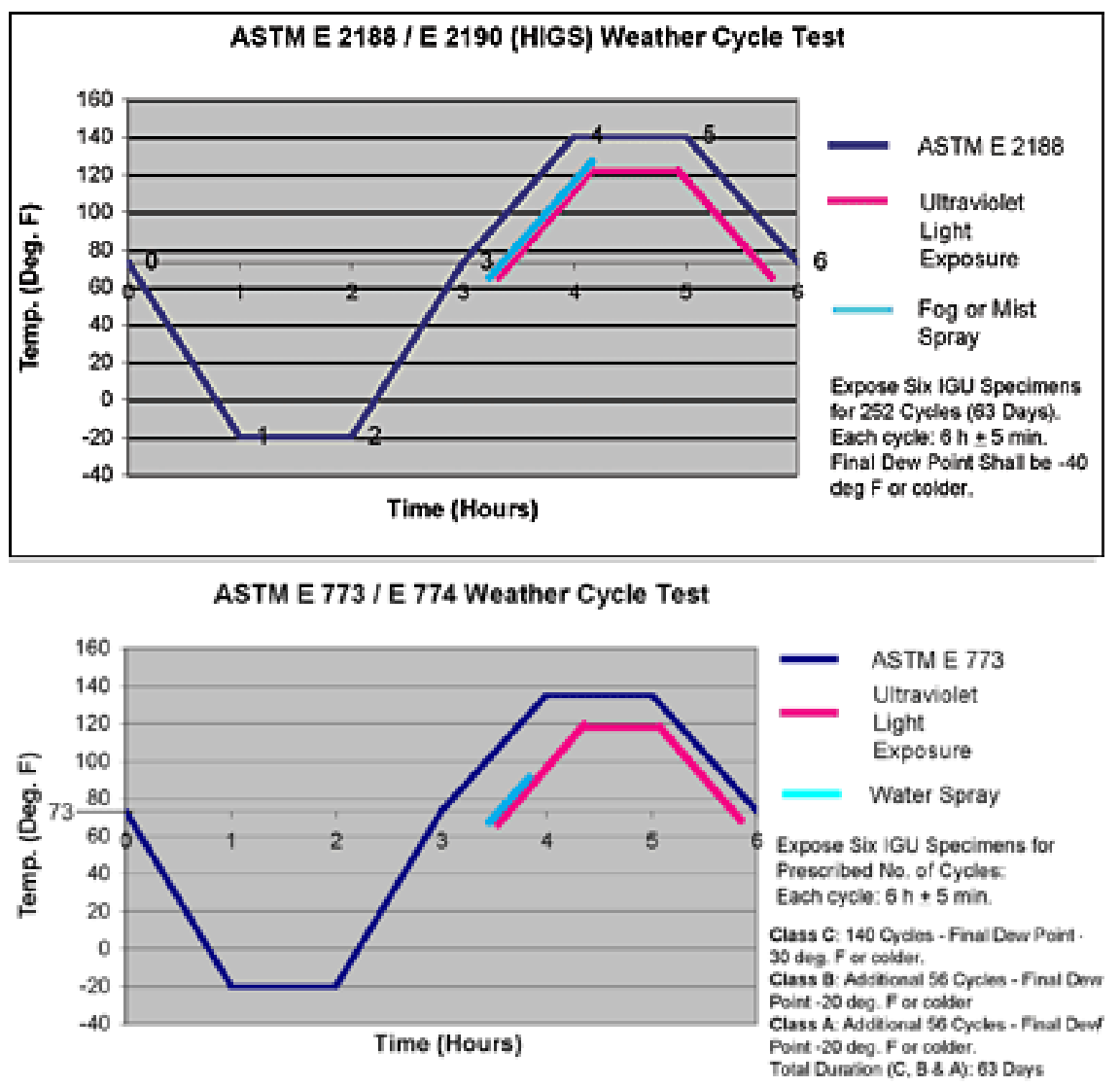

Typical graphical output from weather cycle testing.

\section{A.2.5.3 Volatile Fog Test}

This test is used to show that the components in an IGU will not out-gas a volatile fog, which could result in a deposit on the interior glass surfaces. All three tests use UV radiation and elevated temperatures to accelerate the effects. ASTM E 1887 has a slightly higher UV output than ASTM E 2190 or CGSB 12.8, but it does not place the test samples in a box. In ASTM E 1887, only one corner of the sample sees the UV radiation and elevated temperature. ASTM E 2190 and CGSB 12.8 use a temperature that is $10^{\circ} \mathrm{C}$ higher than ASTM E $774\left(60\right.$ versus $\left.50^{\circ} \mathrm{C}\right)$. However, ASTM E 2190 uses stricter evaluation criteria for viewing the fog. ASTM E 2190 has the observer view the fog at any angle with the sample at arm's length. CGSB 12.8 uses a complicated viewing box with the observer at $2 \mathrm{~m}$ from the sample looking "normal" to the glass surface. 


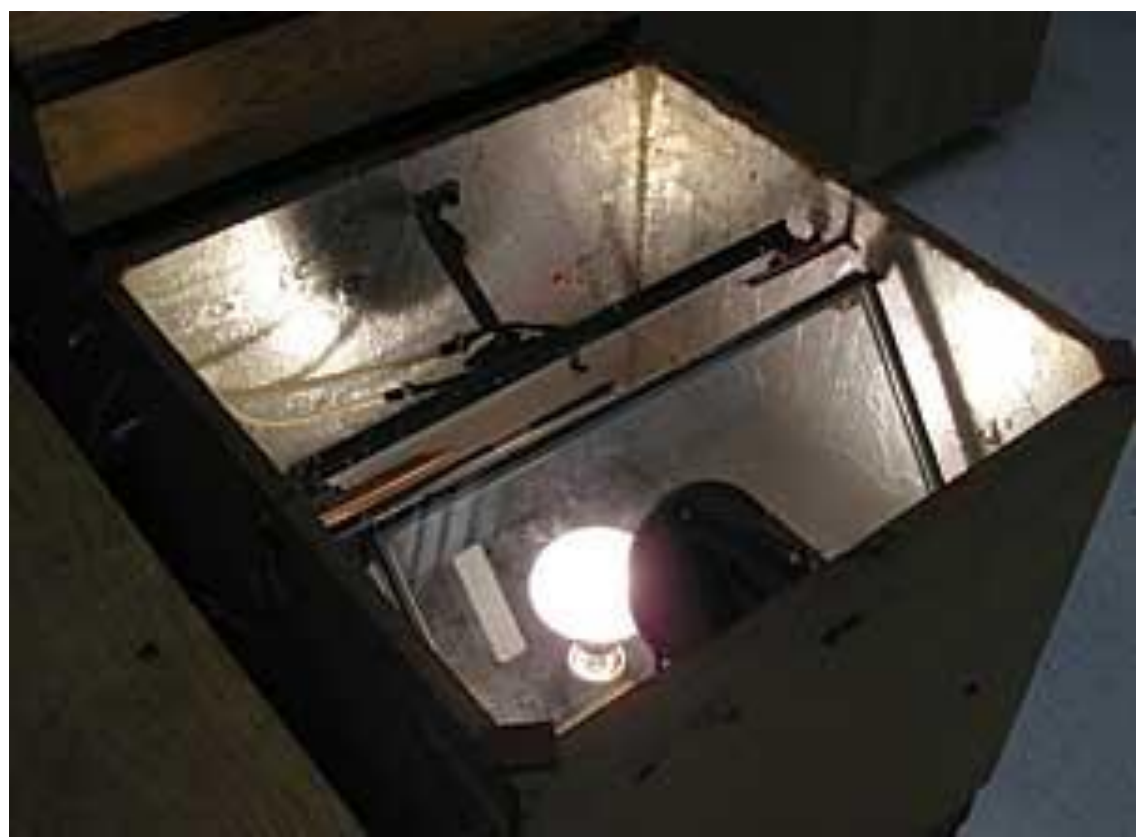

Fog-box used for out-gas testing an insulating glass unit.

\section{A.2.5.4 Argon and Krypton Certification}

Since 1997, IGMA has offered certification for initial gas fill such as argon and krypton in addition to the conventional durability certification testing to the ASTM E 2190 specification.

To participate in this part of the IGMA Certification Program, the insulating glass manufacturer must gas fill all test samples and achieve an initial gas fill level of 90\%, averaged over 10 test specimens in order to achieve this certification designation. Manufacturers who gas fill and want to mark their insulating glass units as IGMA certified must have completed the initial gas fill certification program requirements. Insulating glass manufacturers may get certified to the conventional durability testing, only. Much like the conventional durability testing requirements, the manufacturers are being tested on their ability to fill to a known level (90\%) creating an apple-to-apple platform for the industry. Insulating glass manufacturer's actual production units may or may not be gas filled to this level. The percentage of gas fill required for a particular IGU is dependent on the thermal performance values the IGU manufacturer wants to achieve. Other factors such as the window frame construction materials greatly influence the thermal performance of window products.

Full testing to the current published version of the applicable standard is required before IGMA Certification is granted to a product. Units fabricated and submitted by the manufacturer for certification testing must reflect the manufacturer's actual product unit configuration in all respects. 


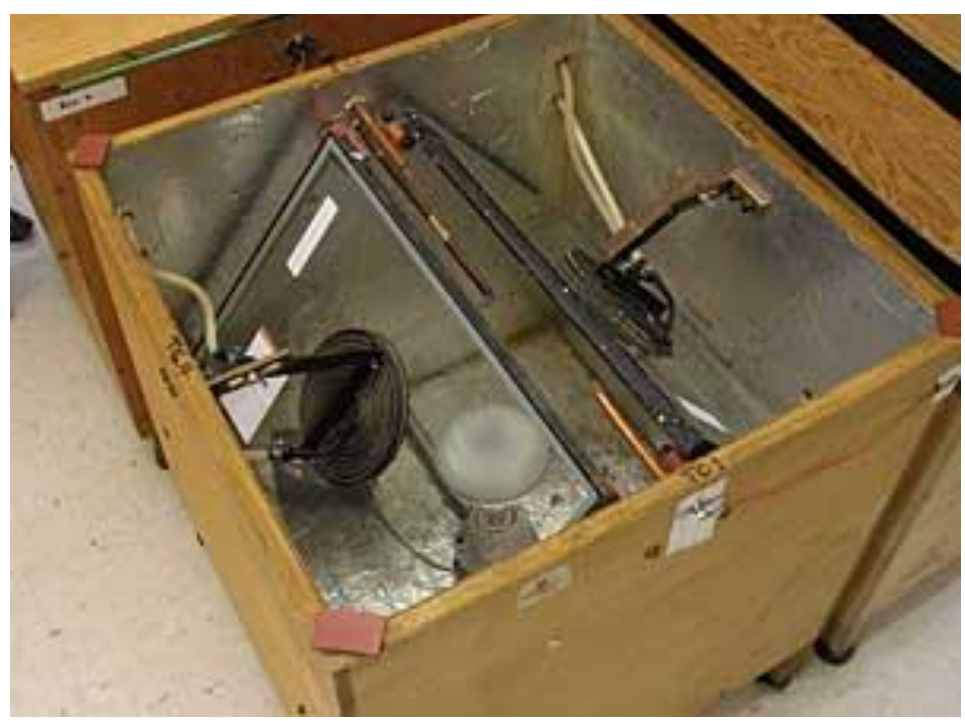

Testing apparatus for testing Argon or Krypton gas fill of insulating glass units.

\section{A.2.6 Heat Flow Meter}

The heat flow meter apparatus establishes steady-state, one-dimensional heat flux through a test specimen between two parallel plates at constant albeit different temperatures. Appropriate calibration of the heat flux transducer(s) with calibration standards is achieved by measurement of the plate temperatures and plate separation. Fourier's law of heat conduction is used to calculate thermal conductivity, and thermal resistivity or thermal resistance and thermal conductance. These instruments are typically used for measuring low and high conductive materials.

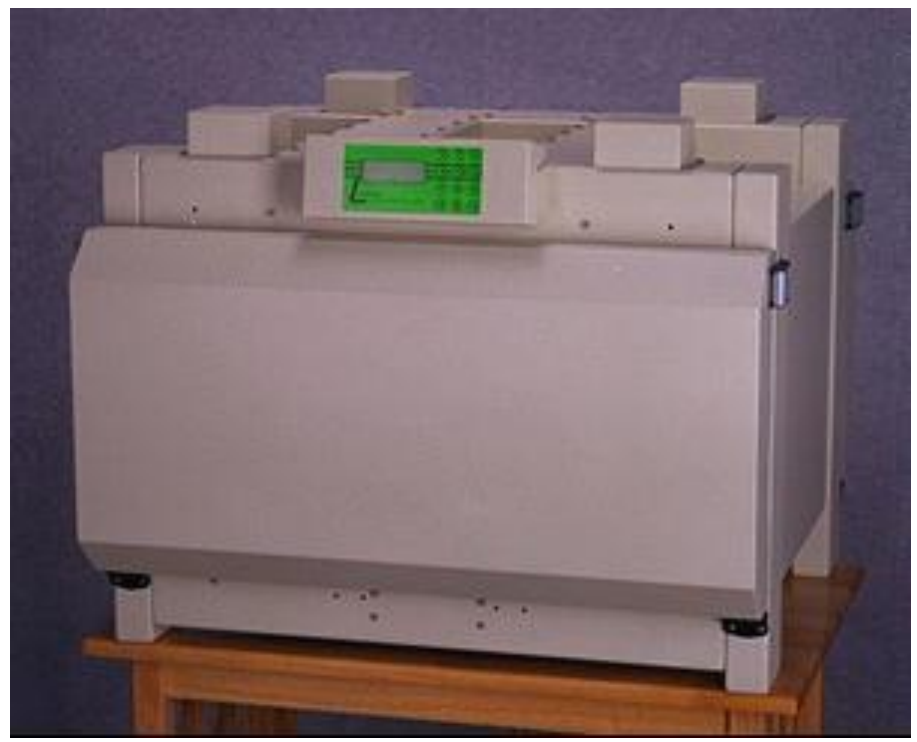

Typical heat flow meter testing apparatus. 


\section{A.2.6.1 Equipment}

LaserComp Fox 600

\section{A.2.6.2 Reference Document}

ASTM C 518, 1045

\section{A.2.7 Reflectometer}

The solar reflectometer helps determine the solar reflectance of flat opaque materials in a laboratory or in the field. The purpose of the test is to provide solar reflectance data required to evaluate temperatures and heat flows across surfaces exposed to solar radiation.

\section{A.2.7.1 Equipment}

- Reflectometer

- Pyranometer

\section{A.2.7.2 Reference Documents}

ASTM C1549, ASTM E1918 and E1918A

\section{A.2.8 Pyranometer}

The pyranometer measures the solar reflectance of various horizontal and low-sloped surfaces and materials in the field. The test method is intended for use when the sun angle to the normal from a surface is less than 45 .

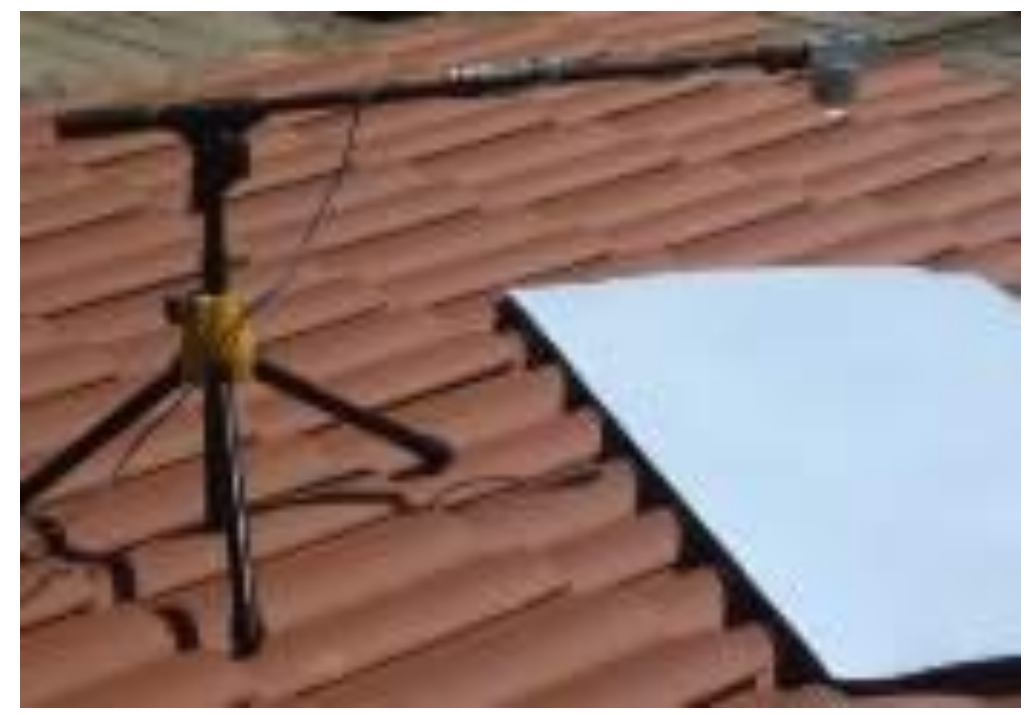

Typical tri-pod-mounted pyranometer. 


\section{A.2.8.1 Equipment}

Pyranometer meeting ASTM E1918

\section{A.2.8.2 Reference Documents}

ASTM E1918 and E1918A

\section{A.2.9 Emissometer}

The portable differential thermopile emissometer is used to determine the emittance of typical materials. The purpose of the test method provides a comparative means of quantifying the emittance of opaque or highly thermally conductive materials near room temperature as a parameter in evaluating temperatures, heat flows, and derived thermal resistances of materials.

\section{A.2.9.1 Equipment}

Portable differential thermopile emissometer meeting ASTM C1371

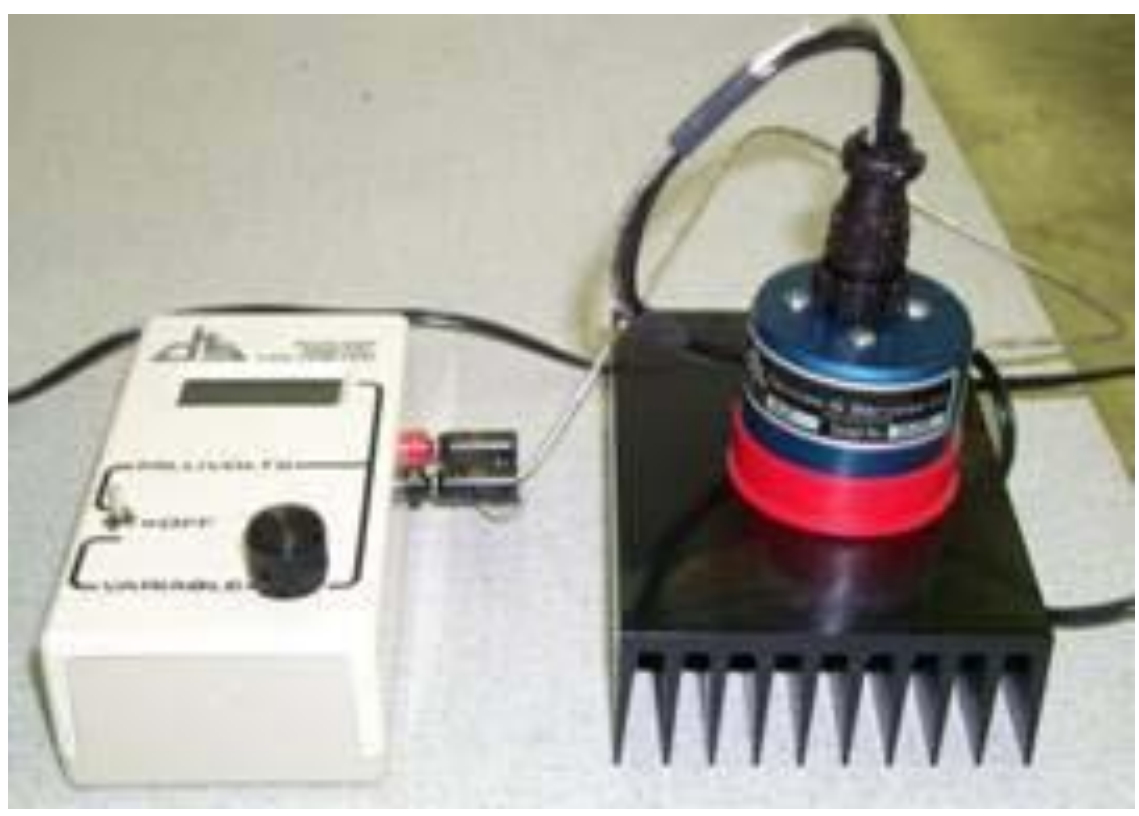

\section{A.2.9.2 Reference Document}

ASTM C1371 


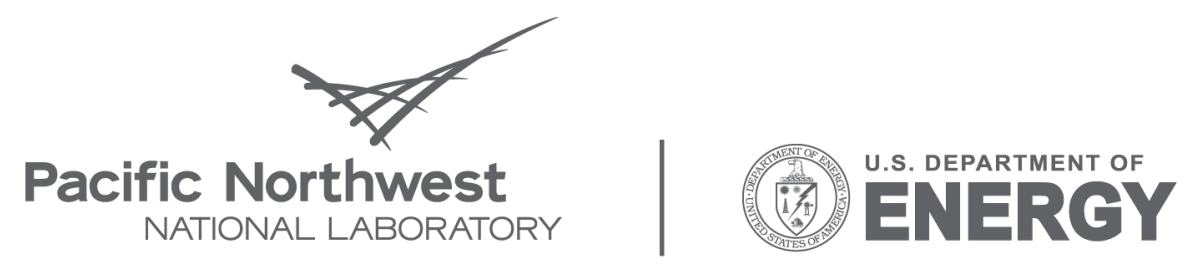

Proudly Operated by Battelle Since 1965

902 Battelle Boulevard

P.O. Box 999

Richland, WA 99352

1-888-375-PNNL (7665)

www.pnl.gov 